University of Nebraska - Lincoln

DigitalCommons@University of Nebraska - Lincoln

Non-Destructive Estimation of Anthocyanins and Chlorophylls in Anthocyanic Leaves

Anatoly A. Gitelson

University of Nebraska at Lincoln, agitelson2@unl.edu

Olga B. Chivkunova

Moscow State University, Moscow, Russia

Mark N. Merzlyak

Moscow State University, Moscow, Russia

Follow this and additional works at: https://digitalcommons.unl.edu/natrespapers

Part of the Natural Resources and Conservation Commons

Gitelson, Anatoly A.; Chivkunova, Olga B.; and Merzlyak, Mark N., "Non-Destructive Estimation of Anthocyanins and Chlorophylls in Anthocyanic Leaves" (2009). Papers in Natural Resources. 225.

https://digitalcommons.unl.edu/natrespapers/225

This Article is brought to you for free and open access by the Natural Resources, School of at DigitalCommons@University of Nebraska - Lincoln. It has been accepted for inclusion in Papers in Natural Resources by an authorized administrator of DigitalCommons@University of Nebraska - Lincoln. 


\title{
NONDESTRUCTIVE ESTIMATION OF ANTHOCYANINS AND CHLOROPHYLLS IN ANTHOCYANIC LEAVES ${ }^{1}$
}

\author{
Anatoly A. Gitelson, ${ }^{2,4}$ Olga B. Chivkunova, ${ }^{3}$ and Mark N. MerzlyaK ${ }^{3}$ \\ ${ }^{2}$ Center for Advanced Land Management Information Technologies, School of Natural Resources, University of Nebraska- \\ Lincoln, Lincoln, Nebraska, USA; and ${ }^{3}$ Department of Physiology of Microorganisms, Faculty of Biology, Moscow State \\ University 119991, GSP-1 Moscow, Russia
}

\begin{abstract}
The anthocyanin and chlorophyll contents in leaves provide valuable information about the physiological status of plants. Thus, there is a need for accurate, efficient, and practical methodologies to estimate these biochemical parameters of vegetation. In this study, we tested the performance and accuracy of several nondestructive, reflectance-based techniques for estimating anthocyanin and chlorophyll contents in leaves of four unrelated species, European hazel (Corylus avellana), Siberian dogwood (Cornus alba $=$ Swida alba), Norway maple (Acer platanoides), and Virginia creeper (Parthenocissus quinquefolia), with widely variable pigment content and composition. An anthocyanin reflectance index, which uses reflectances in the green and red edge spectral bands, and a modified anthocyanin reflectance index, employing, in addition, the near-infrared (NIR) band, were able to accurately estimate leaf anthocyanin for all species taken together with no reparameterization of algorithms. Total chlorophyll content was accurately estimated by a red edge chlorophyll index that uses spectral bands in the red edge and the NIR. These approaches can be used to estimate anthocyanin and chlorophyll nondestructively and allow the development of simple handheld field instrumentation.
\end{abstract}

Key words: anthocyanins; chlorophyll; leaves; nondestructive estimation; reflectance.

Methods to quantify leaf pigment content and composition from remotely sensed data provide a unique nondestructive capability to assess photosynthetic processes in plants and monitor and diagnose foliar conditions and different kinds of environmental stresses. The anthocyanins (Anth) are common pigments in higher plants and responsible for their red coloration. In leaves they localize in vacuoles of epidermal cells or those just below adaxial epidermis, but occasionally, also in the cells of abaxial epidermis and the palisade and spongy mesophyll. Anth biosynthesis may be induced by stresses such as deficiencies in nitrogen and phosphorus, wounding, pathogen infection, desiccation, low temperature, and UV-irradiation. It is generally accepted that Anth fulfill important physiological functions involved in adaptation to and reduction of numerous stresses (Chalker-Scott, 1999; Neill and Gould, 1999; Hoch et al., 2001; Steyn et al., 2002; Close and Beadle; 2003, Pfündel et al., 2006; Hughes and Smith, 2007; Gould et al., 2008). Some lines of evidence suggest that the protective effects of Anth are related to their ability, via screening and/or internal light trapping, to reduce the amount of excessive solar radiation reaching the photosynthetic apparatus (Chalker-Scott, 1999; Steyn et al., 2002; Hughes and Smith, 2007; Gould et al., 2008; Merzlyak et al., 2008; Solovchenko and Merzlyak, 2008).

The chlorophylls (Chl) are essential pigments for the conversion of light energy to stored chemical energy. The amount of solar radiation absorbed by a leaf is a function of the photosynthetic pigment content; thus, $\mathrm{Chl}$ content can directly determine photosynthetic potential and primary production (e.g., Whittaker and Marks, 1975). In addition, the Chl content gives an

\footnotetext{
${ }^{1}$ Manuscript received 26 November 2008; revision accepted 16 June 2009.

This work was supported in part by a grant to A.A.G. from NASA (NNX08AI75G) and to M.N.M. (09-04-00419a) from the Russian Foundation for Basic Research.

${ }^{4}$ Author for correspondence (e-mail: agitelson2@unl.edu)
}

doi:10.3732/ajb.0800395 indirect estimation of the nutrient status because much of the leaf nitrogen is incorporated in chlorophyll (Filella et al., 1995; Moran et al., 2000). Furthermore, leaf Chl content is closely related to plant stress and senescence (Hendry et al., 1987; Merzlyak and Gitelson, 1995; Peñuelas and Filella, 1998; Merzlyak et al., 1999).

The traditional approach for $\mathrm{Chl}$ and Anth determination is with wet chemical methods that involve pigment extraction in organic solvents for subsequent spectrophotometric measurements. However, such laboratory procedures are laborious, time-consuming, and destructive to leaves. The alternative to wet chemical methods is reflectance and/or absorption spectroscopy, which are efficient and nondestructive. Recently, Anth absorption maxima in vivo were found between 537 and $542 \mathrm{~nm}$, and apparent specific Anth absorption coefficients were reported for leaves of several species including those studied in the present work (Merzlyak et al., 2008). It was also found that Anth absorption is linearly related to Anth content below $50 \mathrm{nmol} \cdot \mathrm{cm}^{-2}$.

Nondestructive and remote estimating of pigment content in situ in field conditions should be based on spectral reflectance measurements. To determine the contents of the main leaf pigments, researchers have developed different transformations of reflectance (called vegetation indices) (e.g., Chappelle et al., 1992; Buschmann and Nagel, 1993; Gitelson and Merzlyak, 1994a, b; see also review on Chl estimation by Le Maire et al., 2004 and references therein). For determining leaf Anth content nondestructively, several vegetation indices were designed (e.g., Gamon and Surfus, 1999; Gitelson et al., 2001, 2006; Van den Berg and Perkins, 2005). These indices are based on reflectances $(\rho)$ in a few spectral bands with varying levels of sensitivity to changes in Anth content as well as to the content of other pigments (e.g., Chl).

Van den Berg and Perkins (2005) suggested using the ratio of absorbance $(\alpha)$ in the green band $(530 \mathrm{~nm})$ to the near-infrared (NIR) band $(940 \mathrm{~nm})$ as a proxy for Anth, calling it an anthocyanin content index, ACI $=\alpha_{\text {green }} / \alpha_{\text {NIR }}$. The authors claimed 
that the technique was effective and accurate in estimating Anth content in autumn leaves of Acer saccharum. Steele et al. (2009) modified the method to obtain the ACI (modified ACI, mACI) by using reflectance rather than absorbance for Anth estimation:

$$
\mathrm{mACI}=\rho_{\mathrm{NIR}} / \rho_{\text {green }} .
$$

Gamon and Surfus (1999) suggested using a red/green index, a ratio of reflectances in the red $\left(\rho_{\text {red }}\right)$ and the green $\left(\rho_{\text {green }}\right)$ spectral bands, to estimate Anth content as shown:

$$
\mathrm{red} / \text { green }=\rho_{\text {red }} / \rho_{\text {green }} \text {. }
$$

Anth absorb in situ around 540-550 nm, and the red peak of Chl absorption in situ is around 670-680 nm (Gitelson et al., $2001)$. Thus, the $\rho_{\text {red }} / \rho_{\text {green }}$ ratio estimates Anth content by comparing reflectance in the red region of the spectrum (where only Chl- $a$ and Chl- $b$ absorb) to reflectance in the green region where both $\mathrm{Chl}$ and Anth absorb.

Recently, a conceptual semianalytical model to estimate total Chl, carotenoid (Car), Anth, and flavonoid content in higher plant leaves (Gitelson et al., 2003, 2006) and fruit (Merzlyak et al., $2003,2005)$ was developed. The model relates the content of pigment of interest $\left(C_{\text {pigm }}\right)$ to reflectances at three wavebands $\left(\lambda_{i}\right)$ :

$$
C_{\text {pigm }} \propto\left[\rho^{-1}\left(\lambda_{1}\right)-\rho^{-1}\left(\lambda_{2}\right)\right] \times \rho\left(\lambda_{3}\right) .
$$

To isolate the pigment of interest (e.g., Anth), reflectance in the first band $\left(\lambda_{1}\right)$ should be maximally sensitive to Anth content. To eliminate the effect of absorption by other pigments (e.g., Chl) on $\rho\left(\lambda_{1}\right)$, reflectance in the second spectral band $\rho\left(\lambda_{2}\right)$ should be sensitive to Chl content and not sensitive to Anth content. The difference $\rho^{-1}\left(\lambda_{1}\right)-\rho^{-1}\left(\lambda_{2}\right)$ was called the anthocyanin reflectance index (ARI):

$$
\operatorname{ARI}=\left(\rho^{-1} \text { green }-\rho^{-1} \text { red edge }\right) .
$$

With $\lambda_{\text {green }}$ near $550 \mathrm{~nm}$ and $\lambda_{\text {red edge }}$ around $700 \mathrm{~nm}$, the ARI was used to estimate Anth (Gitelson et al., 2001, 2006). To make ARI less dependent on leaf thickness and density, a third reflectance term $\rho\left(\lambda_{3}\right)$ was introduced. This term is closely related to leaf scattering and is not affected by the absorption by any pigment. For Anth estimation, the following spectral bands were found to be optimal (Gitelson et al., 2001, 2006; Steele et al., 2009): $\lambda_{1}$, green region around $550 \mathrm{~nm} ; \lambda_{2}$, red edge region around $700 \mathrm{~nm} ; \lambda_{3}$, NIR region beyond $760 \mathrm{~nm}$.

Thus, the conceptual model for Anth estimation was presented as the modified anthocyanin reflectance index (mARI) in the form (Gitelson et al., 2006):

$$
\operatorname{mARI}=\left(\rho^{-1} \text { green }-\rho_{\text {red edge }}^{-1}\right) \times \rho_{\text {NIR }} .
$$

The same conceptual model (Eq. 3) with $\lambda_{1}$ in the range of either the green or the red edge and $\lambda_{2}=\lambda_{3}$ in the NIR range was suggested for estimating Chl content (Gitelson et al., 2003, 2006). In Anth-containing leaves, $\lambda_{1}$ in the red edge range should be used. Thus, red edge Chlorophyll Index $\mathrm{CI}_{\text {red edge }}$ with $\rho_{\text {NIR }}$ in the NIR range beyond $760 \mathrm{~nm}$ and $\rho_{\text {red edge }}$ in the range around $700 \mathrm{~nm}$ was recommended to use for Chl retrieval in anthocyanic and Anth-free leaves (Gitelson et al., 2006):

$$
\mathrm{CI}_{\text {red edge }}=\rho_{\mathrm{NIR}} / \rho_{\text {red edge }}-1
$$

The goal of this study was to investigate the overall performance of the four different reflectance-based, nondestructive techniques for estimating Anth and Chl contents in anthocyanic leaves of unrelated species with widely variable pigment content and composition. We found that indices based on conceptual model Eq. 3 accurately estimated $\mathrm{Chl}$ and Anth contents and do not require reparameterization for different species. This study is a basis for nondestructive and remote estimation of $\mathrm{Chl}$ and Anth contents in anthocyanic leaves. The techniques suggested are easy to use in field studies with handheld spectrometers and have a potential for remote estimation of pigment content from aircraft and satellites.

\section{MATERIALS AND METHODS}

Plant material-This study was carried out with the same species and data sets for which previously leaf absorption characteristics were reported (Merzlyak et al., 2008). Healthy and homogeneously colored leaves of European hazel (Corylus avellana L.), Siberian dogwood [Cornus alba L. =Swida alba (L.) Opiz.], Norway maple (Acer platanoides L.), and Virginia creeper [Parthenocissus quinquefolia (L.) Planch.] were randomly collected according to their coloration (see also Gitelson et al., 2001; Merzlyak et al., 2008) in a park at Moscow State University (1992-2008). Anthocyanins were abundant during spring and autumn in sunlit leaves. In juvenile leaves of hazel, Anthcontaining cells were located in both the adaxial and abaxial epidermis. In leaves of other species, Anth were predominantly in the vacuoles of the cell layer of palisade parenchyma (see Merzlyak et al. [2008] for more details).

Pigment analysis - Leaf pigments were analyzed as described in Gitelson et al. (2001), Merzlyak et al. (2008), and Steele et al. (2009). Briefly, one or two discs (1.6 cm in diameter) were cut from leaves and ground with a mortar and pestle in ca $5-8 \mathrm{~mL}$ of methanol in the presence of $\mathrm{CaCO}_{3}$ to prevent $\mathrm{Chl}$ pheophytization. Homogenates were centrifuged for 3-4 min in glass tubes at 3000 $\times g$. The resulting extracts were immediately assayed spectrophotometrically. Specific absorption coefficients of Chl- $a$, Chl- $b$, and total Car reported by Lichtenthaler (1987) were used. A molecular weight of 570 for Car was recognized. Anth content was determined after extract acidification with concentrated $\mathrm{HCl}$. Absorbance at $530 \mathrm{~nm}$ had been corrected for pheophytins contribution: pheophytins $a$ and $b$ were obtained from the corresponding chlorophylls (Fluka Chemie AG, Seelze, Germany), and their absorption coefficients at $530 \mathrm{~nm}$ in acid methanol were found to be 8.17 and $6.35 \mathrm{mM}^{-1} \cdot \mathrm{cm}^{-1}$, respectively. Anth absorption coefficient of $30 \mathrm{mM}^{-1} \cdot \mathrm{cm}^{-1}$ at $530 \mathrm{~nm}$ (Strack and Wray, 1989) was used. The pigment content was expressed on a leaf area basis.

Leaf spectral measurements-Hemispherical adaxial leaf reflectance was recorded by means of a 150-20 Hitachi (Tokyo, Japan) spectrophotometer equipped with a $150 \mathrm{~mm}$ diameter integrating sphere attachment against barium sulphate as a standard. The data were sampled at 2-nm intervals in the 350-800 nm range.

Red/Green, mACI, ARI, and mARI were calculated using average reflectance values in following bands (Gamon and Surfus, 1999; Gitelson et al., 2006; Steele et al., 2009): $\lambda_{\text {green }}=540-560 \mathrm{~nm}, \lambda_{\text {red }}=660-680 \mathrm{~nm}, \lambda_{\text {red edge }}=$ $690-710 \mathrm{~nm}, \lambda_{\mathrm{NIR}}=760-800 \mathrm{~nm} . \mathrm{CI}_{\text {red edge }}$ was calculated using average reflectance in the bands: $\lambda_{\text {red edge }}=690-710 \mathrm{~nm}, \lambda_{\mathrm{NIR}}=760-800 \mathrm{~nm}$. The index values were regressed against the corresponding measured Anth and Chl contents to establish the relationships between them and to assess accuracy of Anth and Chl estimation.

\section{RESULTS AND DISCUSSION}

Pigment content and composition-Analytical Chl and Anth measurements yielded a wide range of pigment contents and composition in analyzed leaves (Fig. 1; Table 1). While Anth content varied broadly in all four data sets (coefficient of variation, $\mathrm{CV}$, was above $67 \%$ ), the dynamic range of $\mathrm{Chl}$ content in each data set was very different. In juvenile hazel leaves, Chl was virtually invariant with $\mathrm{CV}$ below $14 \%$. In dogwood leaves, the CV of Chl was above $100 \%$; however, its content was low-mean Chl was below $6 \mathrm{nmol} \cdot \mathrm{cm}^{-2}$. In maple and creeper leaves, both Anth and Chl changed broadly. In creeper, 

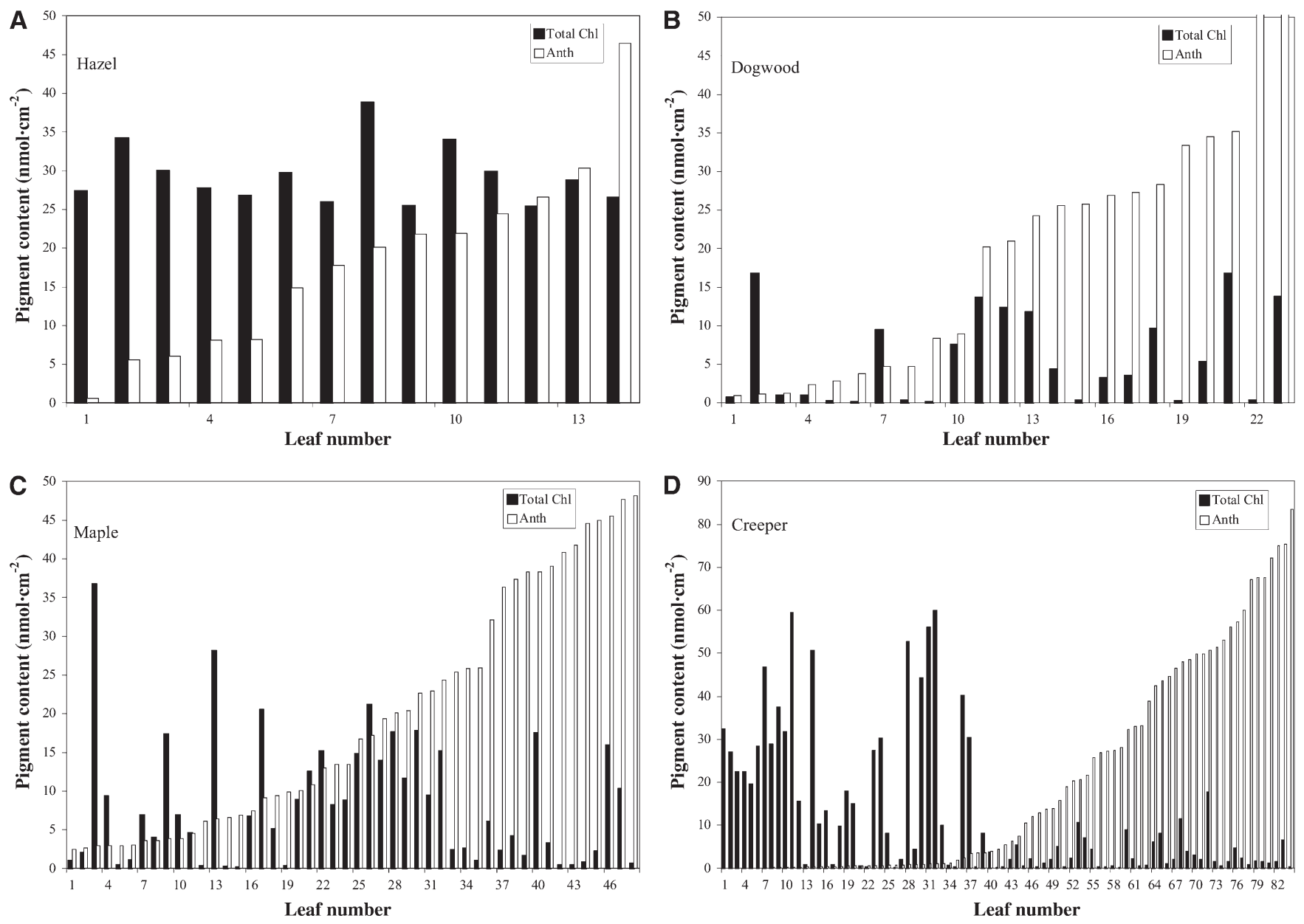

Fig. 1. Total chlorophyll (Chl) and anthocyanin (Anth) contents in data sets for four species (A-D).

Anth content was especially high, and the data set included a number of leaves with a wide variation of Chl against background of low but measurable Anth. As seen in Fig. 1, Anth and Chl contents were not closely related in any of the data sets studied. Thus, four very distinctive data sets were analyzed to test the accuracy of the different nondestructive techniques in estimating Anth and Chl.

Leaf reflectance-Among the species studied, creeper leaves had an especially wide range of color variation from dark green (Fig. 2A) through yellow-reddish (Fig. 2B) to red (Fig. 2C). Reflectance spectra of the three leaf groups were very different.

The green leaves with total $\mathrm{Chl}>30 \mathrm{nmol} \cdot \mathrm{cm}^{-2}$ and Anth $<$ $0.3 \mathrm{nmol} \cdot \mathrm{cm}^{-2}$ had small reflectance in both the blue range (due to Car and $\mathrm{Chl}$ absorption) and the red range (due to $\mathrm{Chl}$ absorption) (Fig. 2A). A distinctive reflectance feature of these leaves is a peak in the green range around $550 \mathrm{~nm}$; in this range, absorption by all pigments is much lower than in the blue and the red ranges, and scattering becomes a significant factor governing leaf reflectance. Another feature is a sharp increase in reflectance beyond $690 \mathrm{~nm}$, the so-called red edge range, due to a decrease in Chl absorption.

Yellow-reddish leaves had low total Chl (below $5 \mathrm{nmol} \cdot \mathrm{cm}^{-2}$ ) and Anth between $0.7-15 \mathrm{nmol} \cdot \mathrm{cm}^{-2}$; the ratio Anth/Chl varied from 0.4 to 40 (Fig. 2B). A wide range of variation in pigment content and composition in these leaves was manifested as a broad variation of reflectance in the visible range. The reflectance in the blue range was much higher than in the green leaves due to lower Chl content. The same was true for the spectra in the red range where reflectance varied from $10 \%$ in yellowgreen leaves to about $50 \%$ in completely yellow leaves. With a decrease in Chl content, the minimum around $675 \mathrm{~nm}$ became less pronounced and almost disappeared in completely yellow leaves (top spectra in Fig. 2B). In situ Anth absorption peaks in the green range around 540-550 $\mathrm{nm}$ (Gitelson et al., 2001; Merzlyak et al., 2008). Thus, with increase in Anth content, reflectance in the green range decreases.

In the red leaves, the effect of Anth absorption can be clearly seen (Fig. 2C): reflectance in the green range is very low (below $7 \%$ ) due to absorption by both pigments, Chl and Anth (Gitelson and Merzlyak, 1994a, b). This overlapping of Chl and Anth absorption in the green range is the main challenge in developing algorithms for nondestructive estimation of Anth content.

Anth estimation by red/green ratio-The red/green ratio (Eq. 2) for Anth estimation is shown for hazel and maple leaves in Fig. 3, and summarized for all species studied in Table 2.The $\mathrm{red} /$ green ratio was accurate in Anth estimation in hazel leaves. In other species, the relationships red/green vs. Anth content 
TABLE 1. Descriptive statistics for leaf pigment contents (in $\mathrm{nmol} \cdot \mathrm{cm}^{-2}$ ) in four species (A-D): anthocyanins (Anth), chlorophyll $a(\mathrm{Chl} a)$, chlorophyll- $b$ (Chl $b$ ), total chlorophyll $(\mathrm{Chl} a+b)$ and carotenoids (Car) in species studied. SD is standard deviation of pigment content in $\mathrm{nmol} \cdot \mathrm{cm}^{-2}$, and $\mathrm{CV}$ is coefficient of variation (\%), $N$ is number of samples. In hazel content of carotenoids was not quantified.

\begin{tabular}{|c|c|c|c|c|c|c|}
\hline Pigment & Min & Max & Mean & Median & SD & $\mathrm{CV}$ \\
\hline \multicolumn{7}{|c|}{ A) Hazel $(N=15)$} \\
\hline Chl $a+b$ & 25.40 & 38.75 & 29.30 & 28.20 & 3.90 & 13.30 \\
\hline Anth & 0.56 & 46.47 & 18.05 & 18.91 & 12.13 & 67.22 \\
\hline Anth/Chl & 0.02 & 1.75 & 0.63 & 0.58 & 0.46 & 72.25 \\
\hline \multicolumn{7}{|c|}{ B) Dogwood $(N=23)$} \\
\hline Chl- $a$ & 0.03 & 12.28 & 4.16 & 2.65 & 4.22 & 101.45 \\
\hline Chl- $b$ & 0.04 & 5.50 & 1.56 & 0.86 & 1.81 & 115.90 \\
\hline Chl $a+b$ & 0.07 & 16.77 & 5.55 & 3.52 & 5.76 & 103.76 \\
\hline Car & 0.73 & 13.83 & 5.44 & 5.56 & 3.90 & 71.66 \\
\hline Anth & 0.90 & 50.77 & 19.23 & 20.99 & 15.66 & 81.43 \\
\hline Car/Chl & 0.33 & 9.94 & 3.12 & 1.50 & 3.01 & 96.49 \\
\hline Anth/Chl & 0.07 & 192.88 & 28.15 & 3.71 & 52.61 & 186.85 \\
\hline \multicolumn{7}{|c|}{ C) Maple $(N=48)$} \\
\hline Chl- $a$ & 0.06 & 26.03 & 6.07 & 4.89 & 5.85 & 96.42 \\
\hline Chl- $b$ & 0.01 & 10.71 & 2.21 & 1.44 & 2.37 & 107.19 \\
\hline Chl $a+b$ & 0.16 & 36.75 & 8.28 & 6.39 & 8.20 & 98.96 \\
\hline Car & 3.19 & 18.24 & 9.21 & 8.91 & 4.16 & 45.14 \\
\hline Anth & 2.50 & 48.21 & 19.48 & 15.10 & 15.20 & 78.02 \\
\hline Car/Chl & 0.14 & 33.55 & 6.10 & 1.29 & 9.41 & 154.18 \\
\hline Anth/Chl & 0.08 & 98.08 & 13.41 & 2.02 & 23.99 & 178.86 \\
\hline \multicolumn{7}{|c|}{ D) Creeper $(N=87)$} \\
\hline Chl- $a$ & 0.06 & 39.87 & 7.93 & 2.61 & 10.78 & 136.01 \\
\hline Chl- $b$ & 0.04 & 20.33 & 3.83 & 1.16 & 5.28 & 137.86 \\
\hline Chl $a+b$ & 0.10 & 59.85 & 11.76 & 3.84 & 16.06 & 136.55 \\
\hline Car & 0.27 & 21.52 & 5.02 & 3.00 & 5.30 & 105.60 \\
\hline Anth & 0 & 83.46 & 20.26 & 5.85 & 24.43 & 120.60 \\
\hline Car/Chl & 0.31 & 4.16 & 1.08 & 0.68 & 0.91 & 84.34 \\
\hline Anth/Chl & 0 & 371.16 & 26.55 & 3.41 & 56.13 & 211.38 \\
\hline
\end{tabular}

were very weak $\left(R^{2}\right.$ was between 0.34 and 0.51 ; Table 2 and Fig. 3B for maple). The relationships of $\rho_{\text {green }}$ to Anth and $\rho_{\text {red }}$ to Anth are helpful in understanding differences in behavior of the red/green in estimating Anth for hazel and other species. In hazel leaves, $\rho_{\text {green }}$ was governed almost solely by Anth content (Chl content was virtually invariant), while $\rho_{\text {red }}$ was governed only by Chl content (Fig. 4A). Thus, the red/green ratio related closely to Anth content in hazel.

In other species, Chl content varied broadly; as a result, the red reflectance changed from $5 \%$ in the green leaves to more than $45 \%$ in the yellow leaves (Fig. 4B for maple). Chl and Anth contents were not related; $\rho_{\text {red }}$ was affected only by $\mathrm{Chl}$ absorption, while $\rho_{\text {green }}$ was affected by absorption of both (Anth and Chl) pigments. Thus, the red/green ratio had a weak relation with Anth (Table 2, Fig. 3B). This is especially notable for low to moderate Anth content because even a small variation in Chl content had a significant impact on $\rho_{\text {green }}$ (Fig. 4B, Table 2).

Anth estimation by $m A C I, A R I$, and $m A R I$ - The $\mathrm{mACI}$ (Eq. 1) is identical to the first term in the mARI (Eq. 5) rewritten as $\mathrm{mARI}=\rho_{\mathrm{NIR}} / \rho_{\text {green }}-\rho_{\mathrm{NIR}} / \rho_{\text {red edge }}$. The $\rho_{\text {green }}$ in the $\mathrm{mACI}$ is affected by absorption of all pigments as well as by leaf scattering that may vary with leaf thickness and density (Gitelson et al., 2006). It was closely related to Anth content in hazel (determination coefficient $R^{2}=0.92$ ), though for each of other species and for all four species together, the relationships were much weaker due to the strong effect of $\mathrm{Chl}$ absorption on reflectance in the green range (Fig. 5). Also noteworthy is a significant de-
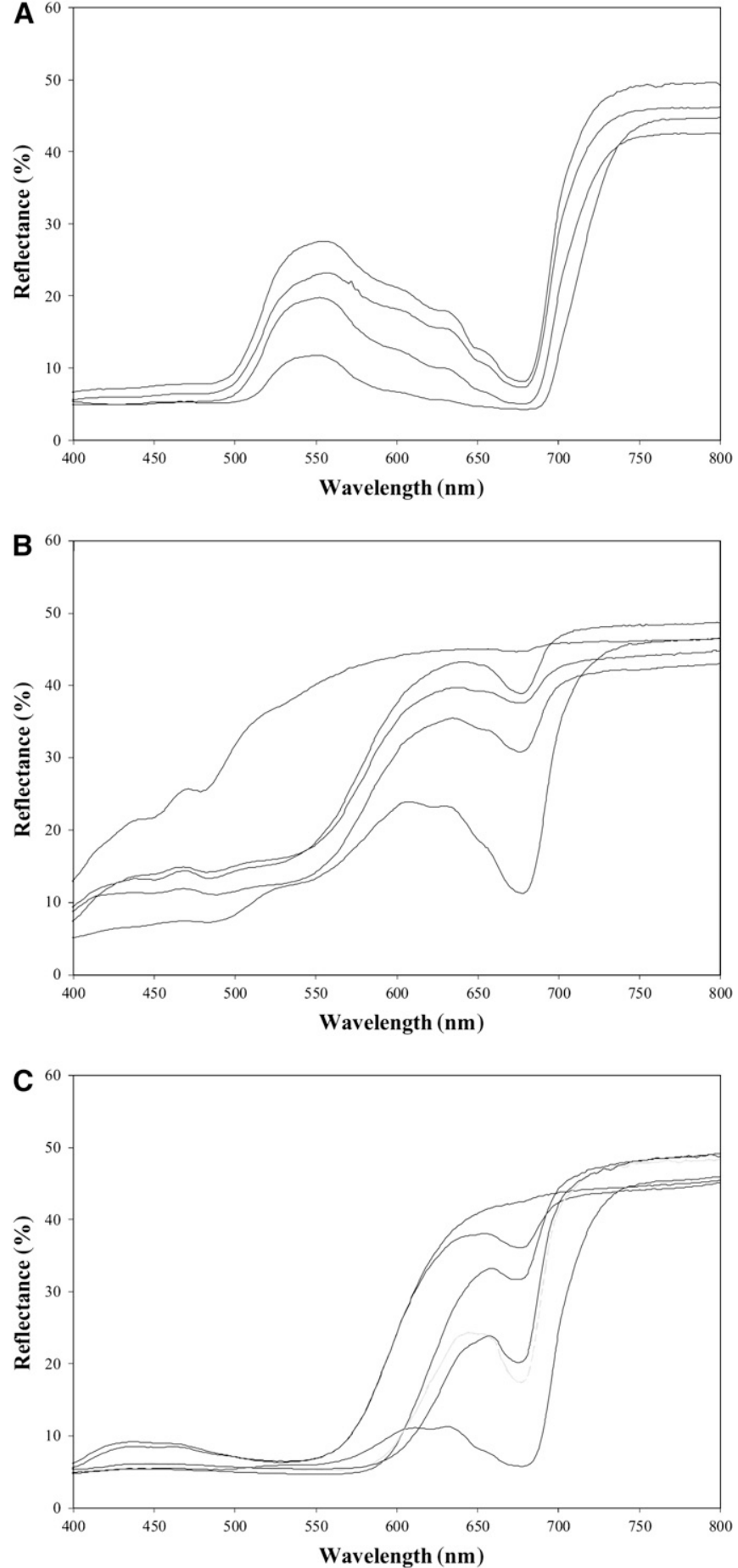

Fig. 2. Effect of anthocyanin content on reflectance spectra of creeper leaves: (A) green leaves with low anthocyanin content, (B) yellow-red leaves, and $(\mathrm{C})$ red leaves.

crease in the sensitivity of $\mathrm{mACI}$ to Anth exceeding $30 \mathrm{nmol} \cdot \mathrm{m}^{-2}$ : the first derivative of $\mathrm{mACI}$ vs. Anth relationship sharply declined when Anth $>30 \mathrm{nmol} \cdot \mathrm{m}^{-2}$ (Fig. 5).

Thus, the main challenge in estimating Anth in leaves with widely variable pigment content and composition is to find a way for (1) accurately subtracting the effects of other pigments (mainly Chl) on $\rho^{-1}$ green, and (2) minimizing uncertainties in 

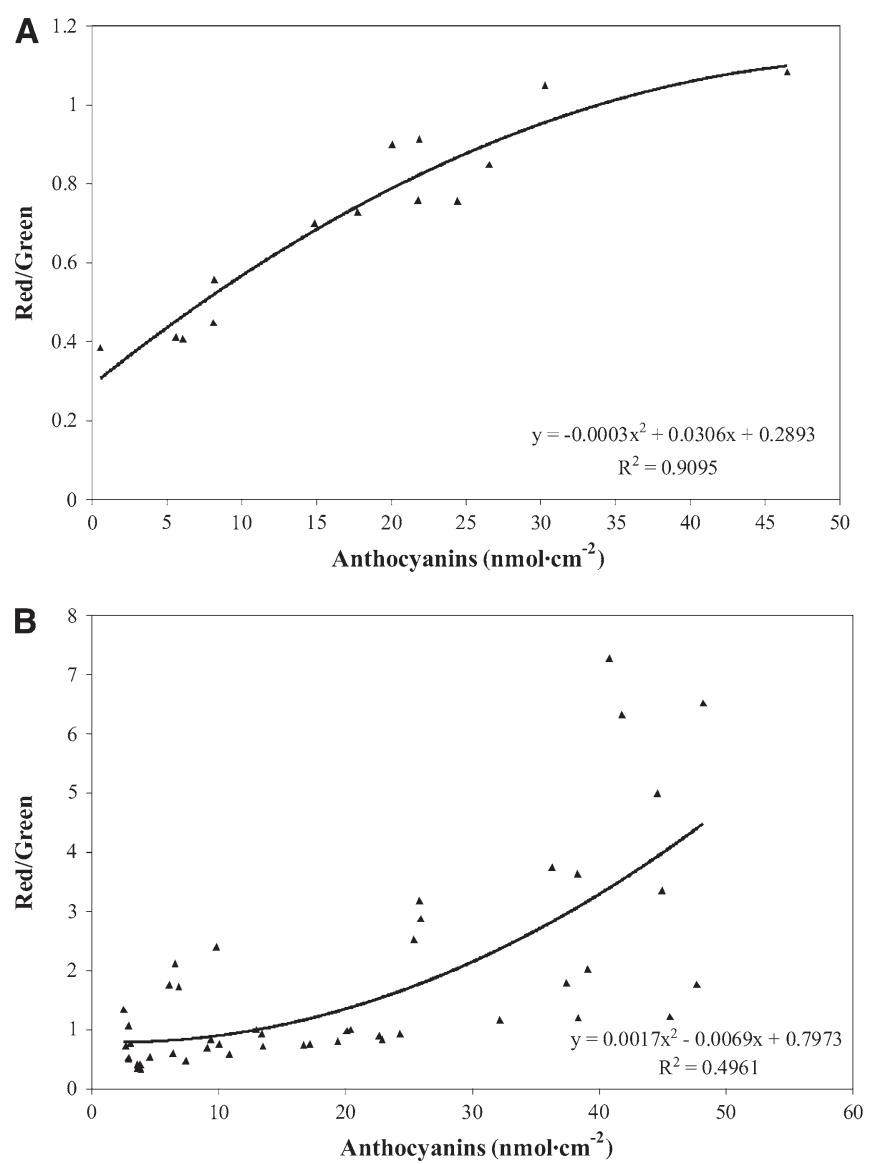

Fig. 3. Performance of the red/green reflectance ratio in estimating anthocyanins content in (A) hazel and (B) maple leaves.

Anth estimation related to variation in leaf thickness. The ARI (Eq. 3) and mARI (Eq. 4) were developed to take into account these effects (Gitelson et al., 2001, 2006).

To demonstrate the concept used in the ARI and mARI for eliminating the effect of $\mathrm{Chl}$ absorption on reflectance in the green range, we plotted the reciprocal reflectance in the green range $\rho^{-1}$ green Vs. the reciprocal reflectance in the red edge, $\rho^{-1}$ red edge (Fig. 6). In Anth-free leaves, absorption in both the green and the red edge ranges is exclusively due to $\mathrm{Chl}$ absorption. It was found that for Anth-free leaves $\rho_{\text {green }} \cong \rho_{\text {red edge }}$ (Chappelle et al., 1992; Gitelson and Merzlyak, 1994b). Hence, the data points representing Anth-free leaves in Fig. 6 occurred along a $\rho^{-1}$ green $\cong \rho^{-1}$ red edge line (so-called green vegetation line; Gitelson et al., 2002). For Anth-free leaves (Anth $<0.3 \mathrm{nmol} \cdot \mathrm{cm}^{-2}$ ), the linear relation $\rho^{-1}$ green vs. $\rho^{-1}$ red edge was very close $\left(R^{2}>0.93\right)$.

In anthocyanic leaves with the same Chl content as in Anthfree leaves, $\rho^{-1}$ green exceeded that of $\rho^{-1}$ red edge due to Anth ab-

TABLE 2. Relationships between the red/green reflectance ratio and anthocyanin content (in $\mathrm{nmol} \cdot \mathrm{cm}^{-2}$ ) for four species studied. $R^{2}$ is determination coefficient

\begin{tabular}{llc}
\hline \hline Species & \multicolumn{1}{c}{ Red/green vs.anthocyanin } & $R^{2}$ \\
\hline Hazel & $y=-0.0003 x^{2}+0.0306 x+0.2893$ & 0.91 \\
Dogwood & $\mathrm{y}=0.0014 x^{2}+0.0080 x+0.8170$ & 0.34 \\
Maple & $\mathrm{y}=0.0017 x^{2}-0.0069 x+0.7973$ & 0.49 \\
Creeper & $\mathrm{y}=-0.0006 x^{2}+0.1016 x+0.7124$ & 0.51 \\
\hline
\end{tabular}
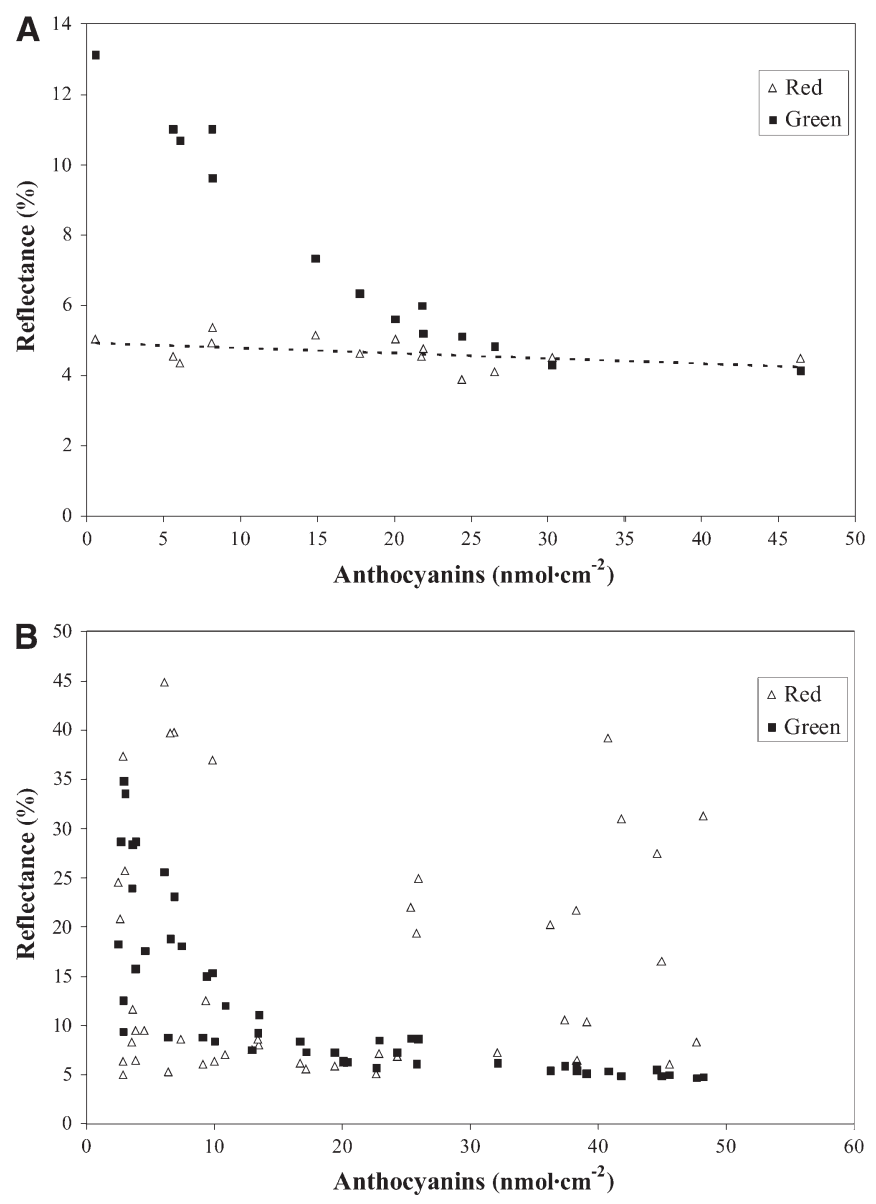

Fig. 4. Reflectances in the green and the red ranges of the spectrum plotted vs. anthocyanin content in (A) hazel and (B) maple leaves.

sorption in the green range; the points representing Anth-containing leaves were placed above the green vegetation line (Fig. 6). Therefore, the distance between the actually measured $\rho^{-1}$ green and the green vegetation line $\left(\rho^{-1}\right.$ green $\cong \rho^{-1}$ red edge $)$ is

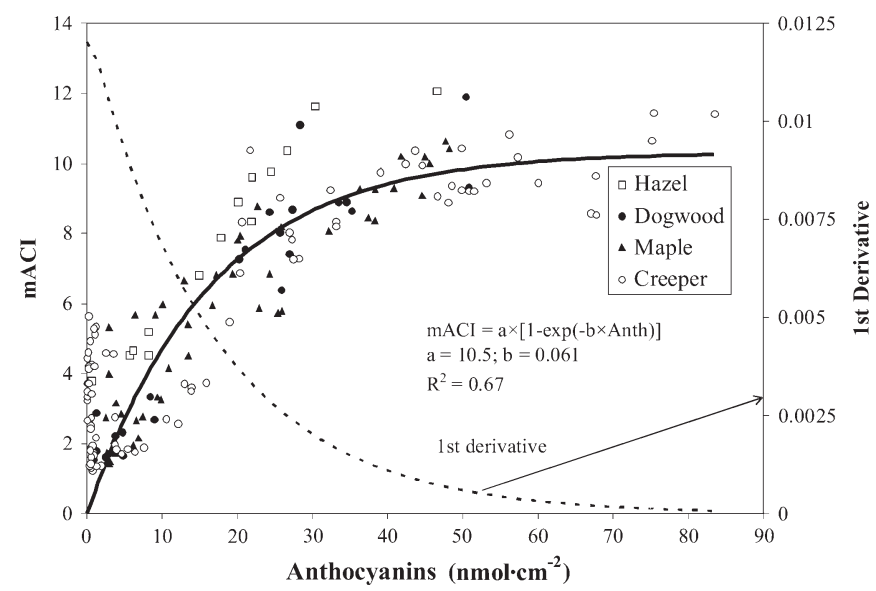

Fig. 5. Performance of the modified anthocyanin content index, mACI, in estimating anthocyanin content for four species studied. Solid line is the best fit function; dashed line is the 1 st derivative of the mACI vs. Anth best fit function. 


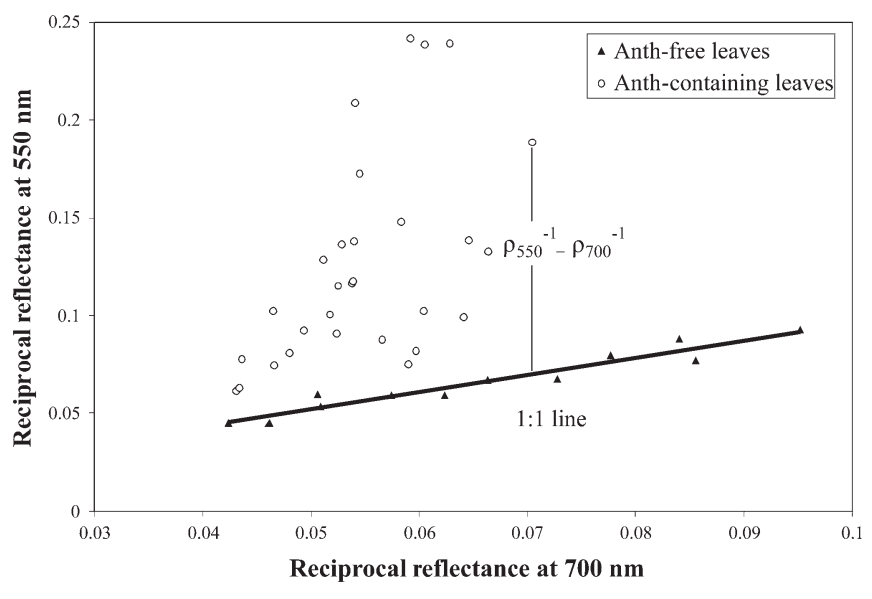

Fig. 6. Relationship between reciprocal of reflectance at $550 \mathrm{~nm}$ and reciprocal of reflectance at $700 \mathrm{~nm}$. Solid line is the best fit function of the relationship for anthocyanin-free leaves $\left(R^{2}>0.93\right)$. The distance of each point from $1: 1$ line [i.e., the difference $\rho\left(\lambda_{\text {green }}\right)^{-1}-\rho\left(\lambda_{\text {red edge }}\right)^{-1}$ ] was found to be a proxy for anthocyanin content.

a measure of Anth content: the larger the distance (i.e., the difference $\rho^{-1}$ green $-\rho^{-1}$ red edge), the higher the Anth content.

To the best of our knowledge, our study is the first attempt to estimate Anth and Chl in different species together using the same algorithm with no reparameterization of the coefficients. To achieve this goal, we needed to understand whether optimal bands determined for one particular species $\left(\lambda_{1}\right.$ in the green range near $550 \mathrm{~nm}, \lambda_{2}$ in the red edge range around $700 \mathrm{~nm}$, and the $\lambda_{3}$ in the NIR; Gitelson et al., 2001, 2006; Steele et al., 2009) remain optimal for other species and whether it is possible to find spectral bands providing minimal uncertainties in Anth estimating in all four species, which differ significantly in pigment composition and content.

We fine-tuned the model to find the optimal spectral bands for the conceptual three-band model (Eq. 3) for each data set studied. To find optimal band $\lambda_{2}$, the root mean square error (RMSE) of the Anth estimation was calculated in the spectral range from 400 to $800 \mathrm{~nm}$ with fixed initial $\lambda_{1}=550 \mathrm{~nm}$ and

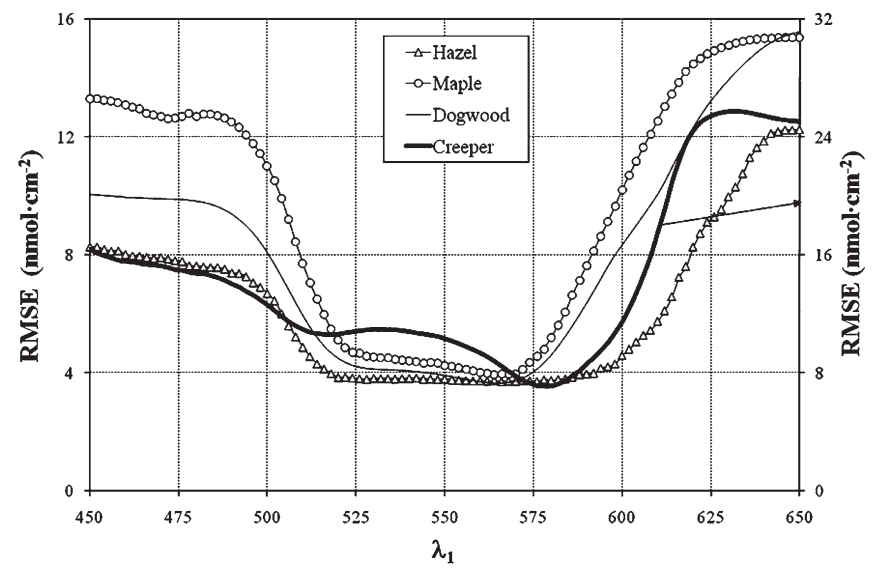

Fig. 7. Fine-tuning the three-band model (Eq. 3) to find optimal spectral band for $\lambda_{1}$. Root mean square error (RMSE) of anthocyanin estimation was calculated in spectral range from 400 to $800 \mathrm{~nm}$ with fixed $\lambda_{2}=$ $700 \mathrm{~nm}$ and $\lambda_{3}=770 \mathrm{~nm}$. Note that the right scale was used for creeper.
TABLE 3. Relationships between anthocyanin reflectance index (ARI) and anthocyanin content (in $\mathrm{nmol} \cdot \mathrm{cm}^{-2}$ ) for four species studied. RMSE is root mean square error of Anth estimation in $\mathrm{nmol} \cdot \mathrm{cm}^{-2}, R^{2}$ is determination coefficient.

\begin{tabular}{llccc}
\hline \hline Species & \multicolumn{1}{c}{ ARI vs. anthocyanin } & $R^{2}$ & RMSE & CV \\
\hline Hazel & $y=-6 \mathrm{E}-05 x^{2}+0.0069 x-0.0143$ & 0.95 & 3.74 & 20.7 \\
Dogwood & $y=-7 \mathrm{E}-05 x^{2}+0.0072 x-0.0126$ & 0.93 & 4.28 & 23.7 \\
Maple & $y=-4 \mathrm{E}-05 x^{2}+0.0053 x-0.0030$ & 0.94 & 4.16 & 21.3 \\
Creeper & $y=0.0026 x+0.0111$ & 0.91 & 8.81 & 43.5 \\
\hline
\end{tabular}

$\lambda_{3}=770 \mathrm{~nm}$. Optimal $\lambda_{2}$ for all species was found in spectral band $700 \pm 10 \mathrm{~nm}$. Then, we found optimal $\lambda_{3}$ calculating RMSE with fixed $\lambda_{1}=550 \mathrm{~nm}$ and $\lambda_{2}=700 \mathrm{~nm}$. For all species, optimal $\lambda_{3}$ was found in a wide NIR band between 760 and $800 \mathrm{~nm}$. Finally, we fixed $\lambda_{2}=700 \mathrm{~nm}$ and $\lambda_{3}=770 \mathrm{~nm}$ and found spectral band $\lambda_{1}$ where RMSE was minimal (Fig. 7). The relationship between RMSE and $\lambda_{1}$ for hazel, dogwood, and maple was almost flat in the range $525-570 \mathrm{~nm}$, showing that the recommended $\lambda_{1}$ in the range around $550 \mathrm{~nm}$ (Gitelson et al., 2001, 2006) was also optimal for these species. However, RMSE for creeper, which was characterized by Anth content exceeding 80 $\mathrm{nmol} \cdot \mathrm{cm}^{-2}$, had a prominent minimum around $575 \mathrm{~nm}$ (right scale in Fig. 7). In addition to high Anth content, this distinction in creeper could be attributed to the accumulation of several spectral forms of Anth (Merzlyak et al., 2008).

In Tables 3 and 4, we present the relationship between ARI and Anth (Eq. 4) and between mARI and Anth (Eq. 5). Reflectances in the bands $\lambda_{2}=700 \pm 10 \mathrm{~nm}$ and $\lambda_{3}=770-800 \mathrm{~nm}$ were used in the calculation for all four species. We used reflectances in the band $\lambda_{1}=550 \pm 10 \mathrm{~nm}$ for hazel, dogwood, and maple and in the band $\lambda_{1}=575 \pm 10 \mathrm{~nm}$ for creeper. Both indices were very accurate in the Anth estimation. The mARI was more accurate for dogwood, maple, and creeper, while ARI was more precise for hazel (Table 3 ).

To retrieve the Anth content for the four species together, we calculated ARI and mARI using spectral bands $\lambda_{1}=550 \pm 10$ $\mathrm{nm}, \lambda_{2}=700 \pm 10 \mathrm{~nm}$, and $\lambda_{3}=770-800 \mathrm{~nm}$. The results for Anth $<50 \mathrm{nmol} \cdot \mathrm{cm}^{-2}$ are presented in Fig. 8. Anth in all species can be estimated by ARI and mARI with no reparameterization of algorithms for any species and yielded RMSE below 4.18 $\mathrm{nmol} \cdot \mathrm{cm}^{-2}$ and $R^{2}>0.94$. The best fit function for both relationships was:

$$
\text { Index }=a \times[1-\exp (-b \times \text { Anth })] .
$$

The coefficients for Eq. 7 were $a=0.293 \pm 0.03$ and $b=$ $0.019 \pm 0.003$ for ARI; $a=13.73 \pm 1.64$ and $b=0.018 \pm 0.003$ for mARI.

Importantly, determination coefficients for the linear relationships for ARI vs. Anth and mARI vs. Anth were higher than 0.92 , and the RMSE of the Anth estimation was $4.34 \mathrm{nmol} \cdot \mathrm{cm}^{-2}$

TABLE 4. Relationships between modified anthocyanin reflectance index (mARI) and anthocyanin content (in $\mathrm{nmol} \cdot \mathrm{cm}^{-2}$ ) for four species studied. RMSE is root mean square error of Anth estimation in $\mathrm{nmol} \cdot \mathrm{cm}^{-2}, R^{2}$ is determination coefficient.

\begin{tabular}{llccc}
\hline \hline Species & \multicolumn{1}{c}{ mARI vs. anthocyanin } & $R^{2}$ & RMSE & CV \\
\hline Hazel & $y=-0.0028 x^{2}+0.3043 x-0.6137$ & 0.95 & 4.00 & 22.1 \\
Dogwood & $y=-0.0027 x^{2}+0.3141 x-0.3194$ & 0.96 & 3.66 & 20.2 \\
Maple & $y=-0.0018 x^{2}+0.2390 x-0.1672$ & 0.95 & 4.05 & 20.8 \\
Creeper & $y=0.0026 x+0.0111$ & 0.92 & 8.13 & 40.0 \\
\hline
\end{tabular}



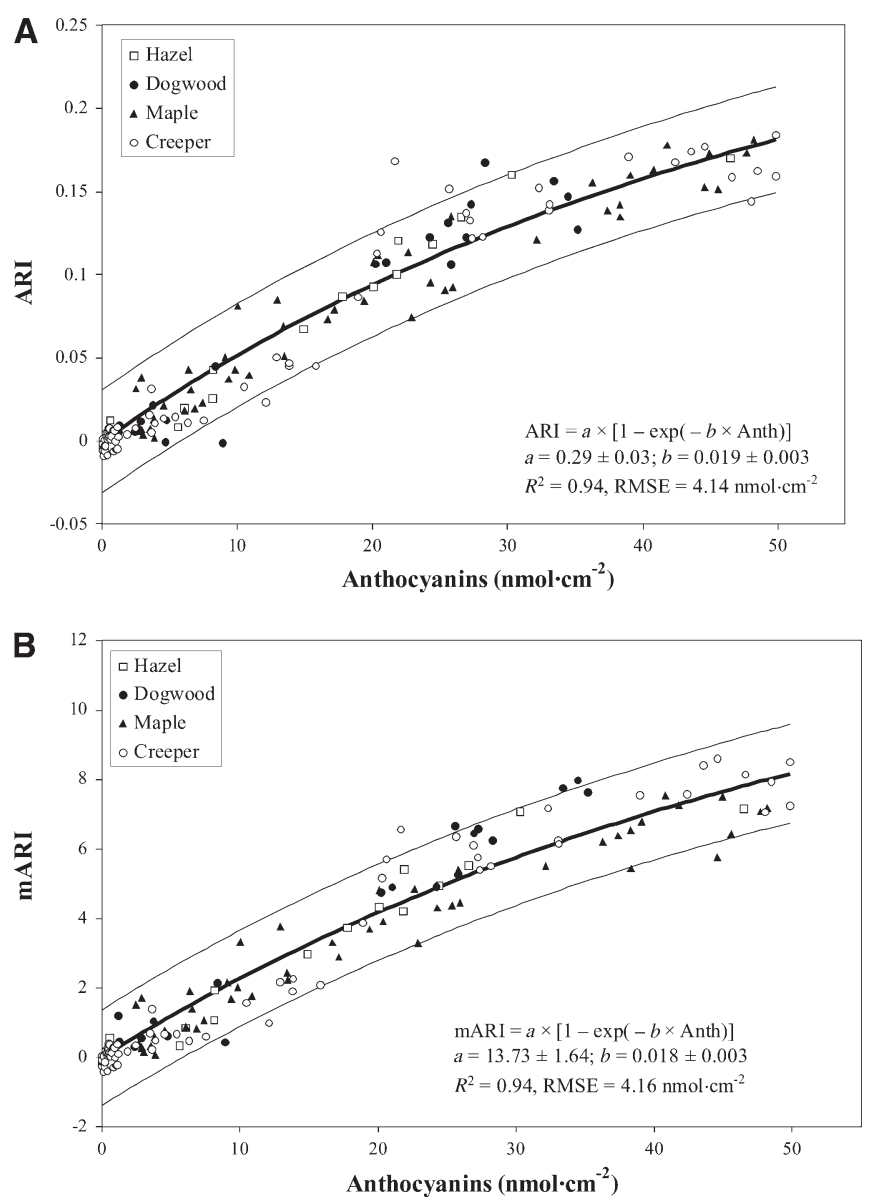

Fig. 8. Performance of the (A) anthocyanin reflectance index (ARI) and (B) modified anthocyanin reflectance index (mARI) for anthocyanin estimation in four species studied with anthocyanin content below 50 $\mathrm{nmol} \cdot \mathrm{cm}^{-2}$. Solid line is the best fit function; thin lines are upper and lower $95 \%$ prediction limits.

for ARI and $4.27 \mathrm{nmol} \cdot \mathrm{cm}^{-2}$ for mARI. Thus, the linear relationships for ARI and mARI with Anth can be used to estimate Anth content below $50 \mathrm{nmol} \cdot \mathrm{m}^{-2}$.

We also estimated Anth content ranging from 0 to 83.5 $\mathrm{nmol} \cdot \mathrm{cm}^{-2}$ for all four species together. The best fit functions for the relationships ARI vs. Anth and mARI vs. Anth were both essentially nonlinear (Fig. 9). Sensitivity of the indices to Anth $>50 \mathrm{nmol} \cdot \mathrm{cm}^{-2}$ declined (see first derivative curve in Fig. 9 , right scale); however, both indices were able to accurately estimate Anth with RMSE below $7.1 \mathrm{nmol} \cdot \mathrm{cm}^{-2}$ for ARI and $6.8 \mathrm{nmol} \cdot \mathrm{cm}^{-2}$ for mARI.

Chlorophyll estimation-For all species together, Chl content was estimated using the red edge chlorophyll index, $\mathrm{CI}_{\text {red edge, }}$ (Eq. 6, Fig. 10). The best fit function $\mathrm{CI}_{\text {red edge }} \mathrm{vs}$. Chl was linear with determination coefficient higher than 0.97 . The $\mathrm{CI}_{\text {red edge }}$ was able to accurately estimate $\mathrm{Chl}$ contents ranging from 0.07 to $59.85 \mathrm{nmol} \cdot \mathrm{cm}^{-2}$ with RMSE below $2.33 \mathrm{nmol} \cdot \mathrm{cm}^{-2}$ in all four species together with no reparameterization of algorithm for each species.

Conclusions-Reflectance-based indices ARI and mARI were found to be effective in the nondestructive estimation of
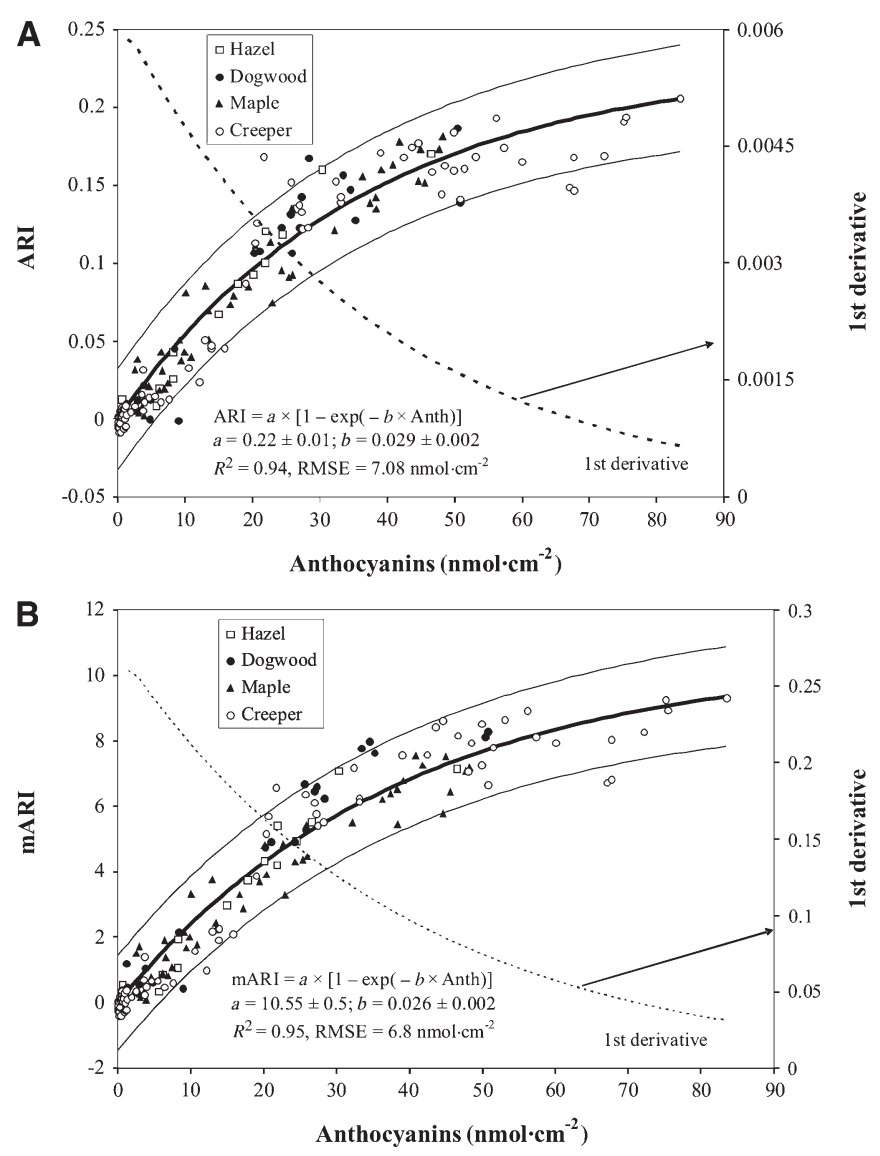

Fig. 9. Performance of the (A) anthocyanin reflectance index (ARI) and (B) modified anthocyanin reflectance index (mARI) for anthocyanin content estimation in different species studied. Solid line is the best fit function; thin lines are upper and lower 95\% prediction limits. Dashed line is the first derivative of the best fit function (right scale).

anthocyanin content in the leaves of four unrelated species despite broad differences in pigment contents and composition. Chlorophyll content was accurately estimated by the $\mathrm{CI}_{\text {red edge }}$ that uses two spectral bands- the red edge and the NIR. None

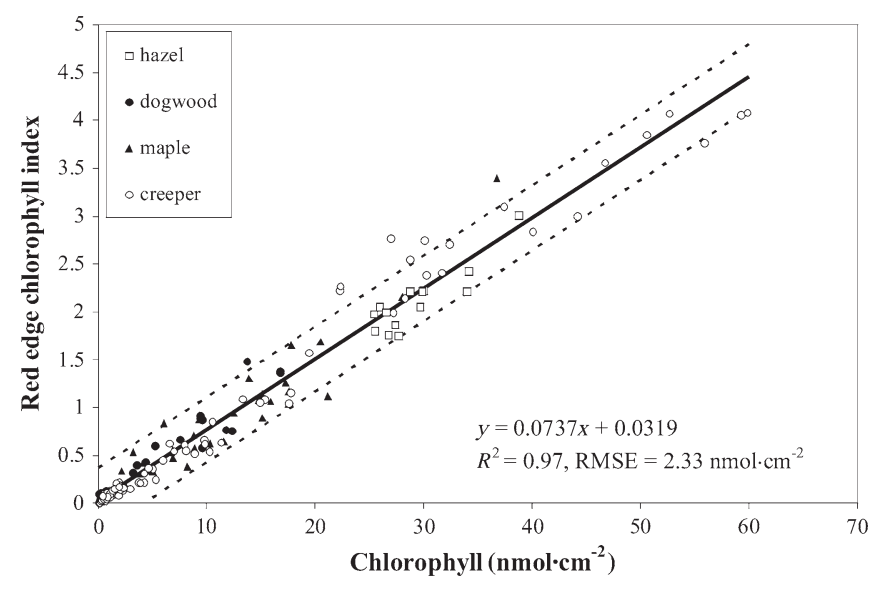

Fig. 10. Chlorophyll content estimation by red edge chlorophyll index for four species studied. Solid line is the best fit function; dashed lines are upper and lower $95 \%$ prediction limits. 
of the three indices (ARI, $\mathrm{mARI}$, and $\mathrm{CI}_{\text {red edge }}$ ) require reparameterization of coefficients for Anth and Chl estimation in the different species. Thus, a radiometer with only three spectral bands $(540-560 \mathrm{~nm}, 690-710 \mathrm{~nm}$, and $760-800 \mathrm{~nm})$ is required for nondestructive Anth and Chl estimation in Anth-containing and Anth-free leaves.

This study can serve as a basis for nondestructive and remote estimation of $\mathrm{Chl}$ and Anth contents in anthocyanic leaves desperately needed to assess the physiological status of vegetation and to detect the early stages of stress. Such an approach can be applied for accurate nondestructive Anth and Chl contents estimation using simple handheld field instrumentation. It also can be used to interpret airborne or satellite imagery to assist scientists in their research and agricultural producers in making informed decisions in managing crops, grasslands, and forests.

\section{LITERATURE CITED}

Buschmann, C., AND E. Nagel. 1993. In vivo spectroscopy and internal optics of leaves as basis for remote sensing of vegetation. International Journal of Remote Sensing 14: 711-722.

ChALKeR-ScotT, L. 1999. Environmental significance of anthocyanins in plant stress responses. Photochemistry and Photobiology 70: 1-9.

Chappelle, E., M. Kim, and J. McMurtrey III. 1992. Ratio analysis of reflectance spectra (RARS): An algorithm for the remote estimation of the concentrations of chlorophyll $a$, chlorophyll $b$ and carotenoids in soybean leaves. Remote Sensing of Environment 39: 239-247.

Close, D. C., And C. L. Beadle. 2003. The ecophysiology of foliar anthocyanin. Botanical Review 69: 149-161.

Filella, I., I. Serrano, J. Serra, and J. Penuelas. 1995. Evaluating wheat nitrogen status with canopy reflectance indices and discriminant analysis. Crop Science 35: 1400-1405.

Gamon, J., AND J. Surfus. 1999. Assessing leaf pigment content and activity with a reflectometer. New Phytologist 143: 105-117.

Gitelson, A. A., U. Gritz, ANd M. N. Merzlyak. 2003. Relationships between leaf chlorophyll content and spectral reflectance and algorithms for non-destructive chlorophyll assessment in higher plant leaves. Journal of Plant Physiology 160: 271-282.

Gitelson, A. A., G. P. Keydan, and M. N. Merzlyak. 2006. Threeband model for noninvasive estimation of chlorophyll, carotenoids, and anthocyanin contents in higher plant leaves. Geophysical Research Letters 33: L11402,

Gitelson, A. A., And M. N. Merzlyak. 1994a. Spectral reflectance changes associate with autumn senescence of Aesculus hippocastanum L. and Acer platanoides L. leaves. Spectral features and relation to chlorophyll estimation. Journal of Plant Physiology 143: 286-292.

Gitelson, A., AND M. MerzlyaK, 1994b. Quantitative estimation of chlorophyll-a using reflectance spectra: experiments with autumn chestnut and maple leaves. Journal of Photochemistry and Photobiology (B: Biology) 22: 247-252.

Gitelson, A. A., M. N. Merzlyak, and O. B. Chivkunova. 2001. Optical properties and non-destructive estimation of anthocyanin content in plant leaves. Photochemistry and Photobiology 74: 38-45.

Gitelson, A. A., R. StaRK, U. Grits, D. RundQuist, Y. KAUfMan, AND D. Derry. 2002. Vegetation and soil lines in visible spectral space: A concept and technique for remote estimation of vegetation fraction. International Journal of Remote Sensing 23: 2537-2562.

Gould, K., D. Kevin, AND C. Winefield [EDS.] 2008. Anthocyanins: Biosynthesis, functions, and applications. Springer, New York, New York, USA.

Hendry, G. A. F., J. D. Houghton, and S. B. Brown. 1987. The degradation of chlorophyll-A biological enigma. New Phytologist 107: 255-302.
Hoch, W. A., E. L. Zeldin, And B. H. McCown. 2001. Physiological significance of anthocyanins during autumnal leaf senescence. Tree Physiology 21: 1-8.

Hughes, N. M., AND W. K. Smith. 2007. Attenuation of incident light in Galax urceolata (Diapensiaceae): Concerted influence of adaxial and abaxial anthocyanic layers on photoprotection. American Journal of Botany 94: 784-790.

Le Maire, G., C. François, and E. Dufrêne. 2004. Towards universal broad leaf chlorophyll indices using PROSPECT simulated database and hyperspectral reflectance measurements. Remote Sensing of Environment 89: 1-28.

Lichtenthaler, H. K. 1987. Chlorophyll and carotenoids: Pigments of photosynthetic biomembranes. Methods in Enzymology 148: 331-382.

Merzlyak, M. N., O. B. Chivkunova, A. E. Solovchenko, and K R. NAQVI. 2008. Light absorption by anthocyanins in juvenile, stressed and senescing leaves. Journal of Experimental Botany 59: 3903-3911.

Merzlyak, M. N., AND A. A. Gitelson. 1995. Why and what for the leaves are yellow in autumn? On the interpretation of optical spectra of senescing leaves (Acer platanoides L.). Journal of Plant Physiology 145: $315-320$

Merzlyak, M. N., A. A. Gitelson, O. B. Chivkunova, and V. Y. RAKITIN. 1999. Non-destructive optical detection of leaf senescence and fruit ripening. Physiologia Plantarum 106: 135-141.

Merzlyak, M. N., A. E. Solovchenko, and A. A. Gitelson. 2003. Reflectance spectral features and non-destructive estimation of chlorophyll, carotenoid and anthocyanin content in apple fruit. Postharvest Biology and Technology 27: 197-211.

Merzlyak, M. N., A. E. Solovchenko, A. I. Smagin, and A. A. Gitelson. 2005. Apple flavonols during fruit adaptation to solar radiation: Spectral features and technique for non-destructive assessment. Journal of Plant Physiology 162: 151-160.

Moran, J. A., A. K. Mitchell, G. Goodmanson, and K. A. StOCKBURGER. 2000. Differentiation among effects of nitrogen fertilization treatments on conifer seedlings by foliar reflectance: A comparison of methods. Tree Physiology 20: 1113-1120.

NeILl, S., AND K. Gould. 1999. Optical properties of leaves in relation to anthocyanin concentration and distribution. Canadian Journal of Botany 77: 1777-1782.

PeÑuelas, J., AND I. Filella. 1998. Visible and near-infrared reflectance techniques for diagnosing plant physiological status. Trends in Plant Science 3: 151-156.

Pfündel, E. E., G. Agati, and Z. G. Cerovic. 2006. Optical properties of plant surfaces. In M. Riederer and C. Müller [eds.], Biology of the plant cuticle, 216-249. Blackwell, Oxford, UK.

Solovchenko, A. E., AND M. N. Merzlyak. 2008. Screening of visible and UV radiation as a photoprotective mechanism in plants. Russian Journal of Plant Physiology: A Comprehensive Russian Journal on Modern Phytophysiology 55: 719-737.

Steele, M. R., A. A. Gitelson, D. C. Rundquist, and M. N. Merzlyak. 2009. Non-destructive estimation of anthocyanin content in grapevine leaves. American Journal of Enology and Viticulture 60: 87-92.

Steyn, W. J., S. J. E. Wand, D. M. Holcroft, and G. Jacobs. 2002. Anthocyanins in vegetative tissues: A proposed unified function in photoprotection. New Phytologist 155: 349-361.

Strack, D., AND V. Wray. 1989. Anthocyanins. In J. B. Harborne [ed.], Methods in plant biology, vol. 1, Plant phenolics, 325-356. Academic Press/Harcourt Brace Jovanovich, London, UK.

Van den Berg, A. K., ANd T. D. Perkins. 2005. Nondestructive estimation of anthocyanin content in autumn sugar maple leaves. HortScience 40: 685-686.

Whittaker, R. H., AND P. L. Marks. 1975. Methods of assessing terrestrial productivity. In $\mathrm{H}$. Lieth and R. H. Whittaker [eds.], Primary productivity of the biosphere, 55-118. Ecological Studies 14 Springer-Verlag, New York, USA. 